\title{
Effective, safe and efficient
}

\author{
Arnold G Vulto
}

'Effective, safe and efficient' is what patients in our hospitals expect from a drug treatment. And we know too well that at times we could do better. It has been my ambition with the European Journal of Hospital Pharmacy (EJHP) to improve all of these aspects in our professional life, with the simple question: does it benefit our patients? This has also dictated the format of the journal; about one-third of the content has an educational purpose (cover stories and features), written by first rate authors; another third is devoted to sharing news from the European Association of Hospital Pharmacists (EAHP) and national associations, in addition to information on best practices (ie, in our Country Focus, Medication Safety Forum, Pan-European Surveys); and, of course, EJHP is also the platform to share research findings: members writing for members.

Since I took responsibility as editorin-chief of this journal in January 2004, I have written more than 80 editorials (see table 1). They have covered a wide range of topics, touching on all aspects of the hospital pharmacy profession. I am convinced that many of you will have noticed that these editorials invariably contained the same message in the end: we are doing this for the benefit of our patients.

This is my final editorial in my capacity as editor-in-chief. When the journal changed publishers in 2011, the Association asked me to stay on as editor to guide the transition. This was not an easy task. Nevertheless, I believe the transition has been completed, more or less successfully, and my expiration date has arrived. It is time to handover the gauntlet to a new editor.

As patient care is the goal of all of our activities, I have chosen this as the topic for my last editorial. With this I wish to make some comments on modern developments in hospital pharmacy: do they really benefit our patients?

Personalised medicine is the new mantra in drug treatment. I believe we can do a lot better with drug treatments, taking into account the individual characteristics of our patients. But how do we get there?

Correspondence to Professor A G Vulto, Department of Hospital Pharmacy, Erasmus Medical Centre, Gravendijkwal 230, Rotterdam 3015CE, The Netherlands; a.vulto@erasmusmc.nl

\section{Editorials by Arnold Vulto}

2004-2012

\section{4}

Automation of the prescribing and dispensing process: where is the evidence of the benefits

In Seville or at home

Perceptions of our Association

A broad view of hospital pharmacy

Unique

Congratulations

\section{5}

Quality

Lisbon 2005

Continuing professional development: a necessity, not a luxury

Multidisciplinary collaboration

How do we care for our patients?

We care!

\section{6}

What's new?

Geneva 2006: Quality = Safety

The largest event devoted to improving patient safety in hospital

Unity within diversity

Triple P: pills, patients and processes

Making cancer history

\section{7}

Risk management

The challenges of new therapies

Nothing new

Extremes

Steeep (safe, timely, effective, efficient, equitable, patient-centred)

Never enough

\section{8}

Achievements

How can you afford NOT to hire a pharmacist....

Sustainability

Collaboration

Think global, act local

The year that was

\section{9}

The price of life

The promise of Basel

Precision medicine

Uncertainty around new cancer treatments

Unaffordable for our patients

New influenza A(H1N1)

vaccination
EJHP cover stories 2004-2012

2004

Automation

Nephrology

HIV/Aids

Transplantation

10th anniversary EJHP

2005

Radiodiagnostic agents

Quality management

Hospital pharmacy and economy

Haemato-oncology (1)

Bone marrow transplantation

Supportive care in Oncology

2006

Innovative drugs in hospitals

Quality and medication safety hand-in-hand

Renal disease and drug treatment

Haemato-oncology (2)

Biopharmaceuticals

The future of oncology treatment

Access to cancer therapy

2007

Multiple sclerosis

New therapies in the 21st century:

challenges for hospital pharmacy

Antifungal drugs

Gene medicines

Paediatric pharmacy

\section{8}

Hospital pharmacists: added value for health

Counterfeit medicines

Pharmaeconomics

Quality in Oncology Pharmacy

Transplantation

Age-related macular degeneration

\section{9}

Breakthrough in oncology

Intensive care therapeutics

IT and automation for the hospital pharmacist

Access to cancer therapy

Clinical trials in Europe

MRI contrast agents

\section{0}

Management of thromboembolism

Photodynamic therapy

Pharmacoeconomics from science to practice

Pharmacotherapy-hospital pharmacists advancing patient care

Clinical application of total parenteral nutrition

Drugs for rare diseases

Biomarkers 
Almost all developments are against a more personal approach to our patients. Personalised medicine entails advanced analytical techniques (such as SNP analysis), advanced IT systems (to inform us of individual traits, such as kidney function and potential interacting drugs) and flexible dosing of medicines. The latter is almost certainly prohibited by the current demands on compounding in hospital pharmacy. Although I believe that GMP is important as a quality standard for drug manufacturing, it is-in the way it is applied in many hospitals-prohibitive in solving individual patient needs. For this reason I am delighted with the cover story, 'Quality of drug preparation in hospital pharmacies', appearing in this, my final issue. As my associate editor V'lain Fenton May, who assumed leadership for this cover story, writes in his article (see page 465) "The core role of a pharmacist is and has always been to supply the patient with the most appropriate medicines according to their needs". It sounds so simple, but as you can read in the news, with increasingly failing drug supplies it is no longer self evident. Simple trials to find simple improvements in drug treatment became history. The implications of the EU guideline 2001/20 and how it is being interpreted are almost prohibitive for the pharmacy's support of these simple trials.

Do I believe in hospital pharmacy? Yes, I have great trust in the professionalism of my colleagues. They all do their best to cope within an almost hostile regulatory environment. Whether it is GCP, GMP, a clinical trials directive or opioid legislation, we all realise too well that in the end the patient will suffer. Because of all of these referees outside the playing field, our patients, at times, get suboptimal treatment. We live and work in a risk evasive environment, overruled by standards, regulations and insurance policies. We have become the hostage of the confection produced by pharmaceutical companies. But in many of my editorials I have emphasised that middle of the road medicine may not be best for those patients that require specialised pharmaceutical care, the raison d'être of hospital pharmacy.

My most sincere hope is that this journal will continue to fight for the professional competence of hospital pharmacists and will not succumb to the dictatorship of guidelines and regulations that will never be able to adequately address the needs of the odd case; there will always be patients needing a specialised drug treatment, requiring the expertise of a well trained hospital pharmacist.

It started with my residents excusing themselves by saying, "It's not in Martindale". Today they say, "I can't find any evidence
2010

Journal club

Innovation at any price?

Imagine hospital pharmacy in 2020

Equity

Genome

Exceptional exception

2011

Scepticism

Lifelong learning

A unifying theory

Prevent or treat

No stakeholders, no solution

Turning the page

\section{2}

A new chapter

Special patients, specialised care

Resolution in patient data

Clinical trials on trial

Effective, safe and efficient

\section{1}

Therapeutic Antibodies

Hospital pharmacists in a changing world: opportunities and challenges

Osteoporosis

Breast cancer overview

Focus on research

\section{2}

Palliative pharmaceutical care

Special patient groups: hospital pharmacists creating standards of care

Practical stability of drugs

New drugs: how much are they worth?

Quality in hospital pharmacy preparation

Special supplements/books:

2006: Patient Safety (distributed in EU parliament)

2007: Multiple sclerosis

2008: Quality in Oncology Pharmacy

(distributed among ESMO-members)

2008: Biopharmaceuticals (together with Prof Dr Huub Schellekens)

2010: Pharmacoeconomics for hospital pharmacists (together with Prof Dr Frans Rutten)

2010: Transplantation for hospital pharmacists (together with Prof, Dr Joseph Grinyó)

in PubMed..." Well, sometimes you are the first to propose a solution for an uneasy drug problem. I was impressed by Roisin O'Hare's contribution on hospital pharmacy education in the UK Country Focus in this issue (see page 485). She writes very inspiringly on how we need to prepare young colleagues for the challenges I depict above. I paraphrase: 'The pharmacy profession should be able to deliver competent practitioners who are able to put patients at the heart of their practice. Pharmacists are required to be adaptable, flexible and should be able to demonstrate the benefit of pharmacy practice on real patient outcomes. Hospital pharmacists have to put continued education and learning into practice, reflecting on their benefit to patients or personal development'.

I have received a lot of support in my work for EJHP. My colleagues in Rotterdam have tolerated me, while I had other priorities (in particular, the final 2 years). I also have to thank my friends on the editorial board who provided ideas and inspiration. The network of country correspondents that we had in addition to our editorial board was our lifeline with the EAHP membership, and they were key in the successes of Medication Safety Forum and the pan-EU surveys. But there is one remarkable character who taught me, as an inexperienced hospital pharmacist, to produce a professional journal that would appeal to the majority of European hospital pharmacists-Mrs Lasia Tang. If anyone appreciates my work as editor, they should know that it was her team that was behind the journal. Mrs Tang provided the inspiration that, coupled with my knowledge of the science and practice of hospital pharmacy, formed the basis of the success of the journal for the past 7 years. In 2008 we achievedrather unexpectedly-indexation, and I see this as her achievement. We have now an impact factor. I wish the new editor-in-chief, Phil Wiffen, all of the success and courage he needs to continue EJHP as the educational servant and publication platform of European hospital pharmacists.

And why? Because only this will result in the greatest benefit for patients who expect the best pharmaceutical care when in hospital. This has been my driving force for the past 10 years as an EAHP board member, as chair of the EAHP scientific committee and as editor of your journal: for the benefit of our patients.

European Journal of Hospital Pharmacy

2012;19:425-426.

doi:10.1136/ejhpharm-2012-000219

Prof Dr Arnold G Vulto

Editor-in-chief EJHP Practice and Science 